\title{
Chronic pain in multi-traumatized outpatients with a refugee background resettled in Norway: a cross-sectional study
}

Dinu-Stefan Teodorescu ${ }^{1,7^{*}}$, Trond Heir ${ }^{2,5}$, Johan Siqveland ${ }^{3,5}$, Edvard Hauff ${ }^{4,5}$, Tore Wentzel-Larsen ${ }^{2,6}$ and Lars Lien ${ }^{1,7}$

\begin{abstract}
Background: Traumatized refugees often report significant levels of chronic pain in addition to posttraumatic stress disorder symptoms, and more information is needed to understand pain in refugees exposed to traumatic events. This study aimed to assess the frequency of chronic pain among refugee psychiatric outpatients, and to compare outpatients with and without chronic pain on trauma exposure, psychiatric morbidity, and psychiatric symptom severity.

Methods: We conducted a cross-sectional study of sixty-one psychiatric outpatients with a refugee background using structured clinical diagnostic interviews to assess for traumatic events [Life Events Checklist (LEC)], PTSD (Posttraumatic Stress Disorder) and complex PTSD [Structured Clinical Interview for DSM-IV PTSD Module (SCID-PTSD) and Structured Interview for Disorders of Extreme Stress (SIDES)], chronic pain (SIDES Scale VI) and psychiatric symptoms [M.I.N.I. International Neuropsychiatric Interview (M.I.N.I.)]. Self-report measures were used to assess symptoms of posttraumatic stress [Impact of Event Scale-revised (IES-R)], depression and anxiety [Hopkins Symptom Checklist (HSCL-25)] and several markers of acculturation in Norway.

Results: Of the 61 outpatients included, all but one reported at least one chronic pain location, with a mean of 4.6 locations per patient. Chronic pain at clinical levels was present in $66 \%$ of the whole sample of outpatients, and in $88 \%$ of the outpatients with current PTSD diagnosis. The most prevalent chronic pain locations were head (80\%), chest (74\%), arms/legs (66\%) and back (62\%). Women had significantly more chronic pain locations than men. Comorbid PTSD and chronic pain were found in 57\% of the outpatients. Significant differences were found between outpatients with and without chronic pain on posttraumatic stress, psychological distress, and DESNOS severity.
\end{abstract}

Conclusions: Chronic pains are common in multi-traumatized refugees in outpatient clinics in Norway, and are positively related to symptomatology and severity of psychiatric morbidity. The presence of chronic pain, as well as comorbid chronic pain and PTSD, in psychiatric outpatients with a refugee background call for an integrated assessment and treatment for both conditions.

Keywords: Chronic pain, Comorbid chronic pain and PTSD, Resettled refugees, Traumatized refugees, DESNOS

\footnotetext{
* Correspondence: d.s.teodorescu@medisin.uio.no

${ }^{1}$ Department of Public Health, Hedmark University College, Elverum, Norway

${ }^{7}$ Innlandet Hospital Trust, PO Box 104, N-2381 Brumunddal, Norway

Full list of author information is available at the end of the article
} 


\section{Background}

Many refugees have been exposed to multiple traumas (Steel et al. 2002; Elklit et al. 1998) and are at high risk for developing Posttraumatic Stress Disorder (PTSD) (Roth et al. 2006; Ai et al. 2002; Lavik et al. 1996; Ferrada-Noli et al. 1998). Among the most traumatizing exposures with a particularly high risk for later PTSD symptom development are torture and war trauma (Johnson and Thompson 2008; Jaranson et al. 2004). Besides mental health problems, somatic pain problems are also common in refugees (Gerritsen et al. 2006).

Pain in the aftermath of a traumatic event has been identified as a risk factor for the development of PTSD (Norman et al. 2008), and often PTSD and chronic pain are concomitant (Moeller and Bertram et al. 2012; Beck and Clapp 2011; Beckham et al. 1997). Patients seeking treatment for chronic pain also have higher rates of PTSD (Villano et al. 2007; Dunn et al. 2011; Sharp 2004; Andersen et al. 2012). The prevalence of pain in veterans seeking treatment for PTSD was found to be higher than the prevalence of PTSD in veterans seeking treatment for pain (Asmundson et al. 2002). This difference may be explained by the nature of traumatic events that are often associated with physical injuries, such as war injuries or torture. The severity of PTSD symptoms was found to be related to higher intensity of pain (Hermansson et al. 2001). The highest rates of chronic pain are found in torture exposed refugees (Carinci et al. 2010; Thomsen et al. 2000; Williams et al. 2010), and chronic pain in tortured refugees has been found to have a strong impact on daily functioning (Prip et al. 2011).

PTSD and chronic pain comorbidity is high in refugees, and a Norwegian study reported chronic pain prevalence of $76 \%$ in a clinical sample of refugees with PTSD symptoms (Dahl et al. 2006), a finding in line with similar research from Denmark (Carlsson et al. 2005), Great Britain (Taylor et al. 2013), and Germany (Liedl et al. 2010).

A Swedish study investigated gender differences in somatic pain and found that being a female, regardless of ethnicity (Kurdish-born or Swedish-born), resulted in higher odds for poor psychological well-being (Taloyan et al. 2008). This gender difference in psychological well-being among refugees is also consistent with a Norwegian study (Hjellset et al. 2011). The Oslo Immigrant Health study found that musculoskeletal disorders in immigrant groups were up to 8 -fold higher as compared with Norwegians, with immigrant women reporting greater proportions than men (Kummar et al. 2008).

The impact of stress on both mental and physical health has been acknowledged for many years, a relationship influenced by biological, psychological, behavioral and social determinants (Schneiderman et al. 2005).

Several models have been developed in order to explain the complex interactions between pain and PTSD such as the "mutual maintenance theory" (Sharp and Harvey 2001), the "shared vulnerability model" (Asmundson et al. 2002), the "fear-avoidance model" (Norton and Asmundson 2003) and the "perpetual avoidance model" (Liedl and Knaevelsrud 2008).

We shall explain in more depth only one model which we find most relevant for our study, the mutual maintenance theory. This theory proposes that PTSD and chronic pain maintain or exacerbate each other through seven mechanisms: attentional and reasoning biases, anxiety sensitivity, reminders of the trauma, avoidance, depression and reduced activity levels, anxiety and pain perception and cognitive demand from symptoms limiting the use of adaptive strategies. Attentional biases are common in both PTSD and chronic pain, and outpatients with PTSD will more often direct their attention towards the pain sensation, which would increase the perception of pain. Anxiety sensitivity, which implies a fear of anxiety-related bodily sensations, will amplify the anxiety responses associated with exposure to trauma and the sensation of pain (Taylor 2004). Reminders of the trauma contribute to physiological arousal and other symptoms of PTSD, and the chronic pain is perceived as a reminder of the past trauma. Avoidant coping styles, including both behavioral and cognitive avoidance strategies, are employed in both PTSD and chronic pain leading to the maintenance of symptoms of deconditioning and disability in pain patients, and the maintenance of intrusive symptoms and associated arousal in PTSD patients (Waddell et al. 1993; Foa et al. 1989). Depression and reduced levels of activity are common in both chronic pain and PTSD outpatients, leading to increased levels of disability in chronic pain outpatients, and to a lack of exposure to trauma related stimuli in PTSD outpatients (Waddell et al. 1993). The anxiety and pain perception mechanism proposes that PTSD, which is characterized by anxiety, will directly influence the perception of pain (Difede et al. 1997; Defrin et al. 2008). Finally, an overload of cognitive capacity employed in reducing the perception of pain leads to a limited use of adaptive strategies for controlling the pain (Bryant et al. 2001). Thus, in the case of chronic pain, physiological arousal, cognitive catastrophizing, and behavioral avoidance components contribute to the maintenance of PTSD, while in the case of the PTSD, physiological arousal, emotional numbing and behavioral avoidance components contribute to the maintenance or aggravation of chronic pain. Evidence from research for the mutual maintenance between symptoms of PTSD and chronic pain has been found both in longitudinal and cross sectional studies (Jenewein et al. 2009; Liedl et al. 2010).

The perpetual avoidance model may further explain the mutual maintenance of the symptoms of chronic pain and PTSD, by the PTSD re-experiencing symptom triggering arousal, which generates muscle tension in the body and leads to the development of chronic pain. The experience 
of pain in and of itself is distressing and an avoidance strategy may be employed to cope with this pain, which may in turn trigger the re-experiencing component of PTSD, and thus the mutual maintenance of chronic pain and PTSD. This mechanism of mutual maintenance between PTSD symptoms and chronic pain has indirect support from studies in veterans with and without PTSD which report more physical symptoms in veterans with PTSD (Baker et al. 1997; O'Toole and Catts 2008).

Refugees are often exposed to multiple or complex traumas over longer periods of time and due to this can develop Complex PTSD or Disorders of Extreme Stress Otherwise Not Specified (DESNOS). Complex PTSD has been identified in traumatized refugees (Palic and Elklit 2014) and tortured refugees (Teegen and Vogt 2002), and since 1992 has been proposed as a separate diagnostic category in order to accommodate changes in six self domains [(I) alterations in affect and impulse regulation; (II) alterations in consciousness or attention; (III) alterations in self-perception; (IV) alterations in perception of the perpetrator (not required for a DESNOS diagnosis); (V) alteration in relations with others; (VI) somatization, and (VII) alterations in systems of meaning] (Herman 1992). Complex PTSD or DESNOS was not included in the DSM-V (American Psychiatric Association 2013), but the ICD-11 Beta Draft has proposed the following definition of complex post-traumatic stress disorder or DESNOS: "Complex PTSD is a disorder that arises after exposure to a stressor typically of an extreme or prolonged nature and from which escape is difficult or impossible. The disorder is characterized by the core symptoms of PTSD as well as the development of persistent and pervasive impairments in affective, self and relational functioning, including difficulties in emotion regulation, beliefs about oneself as diminished, defeated or worthless, and difficulties in sustaining relationships" (WHO 2014).

Comorbid chronic pain and PTSD in psychiatric outpatients with a refugee background resettled in Western countries have not been investigated in many studies. The few that exist are limited in that they have made use of short questionnaires for establishing a PTSD diagnosis, and employed interpreters with a limited knowledge of the questionnaires. (Dahl et al. 2006; Hermansson et al. 2002). To improve upon this previous work, the present investigation used a clinical diagnostic structured interview to assess PTSD, in addition to assessing a wide range of psychiatric diagnoses. The aims of the study were:

1. To assess the frequency of clinical levels and location of chronic pain, and comorbid PTSD and chronic pain in psychiatric outpatients with a refugee background.

2. To compare outpatients with and without chronic pain on demographic, acculturation (Norwegian language proficiency, employment, social integration in Norway and ethnic community), trauma exposures, psychiatric morbidity, and psychiatric symptom severity variables.

3. To compare outpatients with and without PTSD on chronic pain locations.

We evaluated the following hypotheses:

1. The group of patients with chronic pain will report more psychiatric morbidity and more severe symptomatology than the group without chronic pain.

2. Women will report more chronic pain at clinical levels, more locations of pain, and more comorbid PTSD and chronic pain than men.

3. Patients with a PTSD diagnosis will have more chronic pain at clinical levels than patients without PTSD.

\section{Method}

\section{Participants}

Participants were recruited from 17 general psychiatric outpatient clinics in South-Eastern Norway between November $1^{\text {st }} 2008$ and November $1^{\text {st }} 2009$. The outpatients were informed about the study by their therapists who were making referrals to the study. A total of 63 patients were asked to participate in the study, two declined the invitation, and 61 outpatients, 25 (41\%) of whom were women, accepted to participate. None of the patients withdraw their consent during the study. After the referral from the outpatients' therapists, the researcher (the first author) evaluated the inclusion criteria in the study: previous exposure to at least one traumatic event according to criteria from the DSM-IV (American Psychiatric Association 2000), having a permanent residence in Norway, and having sufficient proficiency in spoken and written Norwegian. The exclusion criteria included suffering from a serious medical condition (neurological or organic), active psychotic episode, high current suicide risk, not having a permanent residence in Norway and having insufficient knowledge of the Norwegian language. Written informed consent was obtained from all participants at the first meeting with the researcher (the first author) prior to the clinical interview, and they were compensated 200NOK (EUR 25) for their study participation, and all travel expenses were covered as well. The outpatients were interviewed in the psychiatric clinics where they used to receive treatment, and the clinical interviews lasted for on average two hours. At the clinical interview the researcher assessed the inclusion criteria by means of an anamnestic interview and during this clinical interview the degree of knowledge of the Norwegian language was assessed directly by the researcher. At the end of the clinical interview the outpatients received a stamped envelope which included the Questionnaire (a set of self-reported questionnaires) to be completed at home and posted within a week. One telephone follow-up reminder was made if the Questionnaire 
was not returned after one week. The study protocol was approved by the Committee for Medical Ethics of Health Region East of Norway (REK-East).

\section{Measures}

The first author collected data from patients through a structured clinical interview, followed by the patient's completion of a self-report Questionnaire consisting of a set of questionnaires. Five outpatients failed to return the selfreport Questionnaire, and the total scores of IES-R and HSCL-25 are based on the scores of the outpatients who returned the self-report Questionnaire.

National origin was assessed with the question from the self-report Questionnaire" Which country is your country of origin? We created the variable "Regional origin" by grouping the countries into three categories: 1) Eastern Europe; 2) Africa + Middle East; 3) Other. The "Other" category included refugees from Asia and Latin America.

Employment was assessed by one question from the self-report Questionnaire "Are you employed and paid for it?" with three response alternatives: (1) "Full-time paid employment"; (2) "Part-time paid employment"; (3) "No paid employment".

Having friends was measured with the question from the self-report Questionnaire: "How many good friends do you have?" ("Count those whom you can talk to in confidence and who can help you when you need help"). We created a categorical variable "Having friends" by grouping the number of friends into two categories: 1) "0" friends 2) all numbers of friends ranging from "1" friend to "11" friends.

To assess integration into Norwegian society, Social integration in Norway was measured by an index based on four items from the self-report Questionnaire: (1) Knowledge of the Norwegian language; (2) Reading Norwegian newspapers in the last year; (3) Visited by Norwegians in the last year; (4) Received help/support from Norwegians in the last year. Items 2 to 4 had 4 response alternatives, higher scores indicating higher acculturation. The response alternatives were (1) "Never"; (2) "Not very often"; (3) "Weekly"; (4) "Daily". Item 1 had 5 response alternatives: (1) "Very bad"; (2) "Bad"; (3) "Medium"; (4) "Good"; (5) "Very good". We collapsed the response alternatives (1) and (2) for Item 1 into one category. An index score was calculated by adding the scores for the four items, with a possible range from 4 to 16 and higher scores indicating higher integration.

We measured Social integration in the ethnic community (non-Norwegian community) in Norway with two items from the self-report Questionnaire: (1) "How often in the last year have you participated in meetings arranged by your countrymen?" and (2) "Reading newspapers in your first language in the last year". The items had 4 response alternatives: (1) "Never"; (2) "Very seldom"; (3) "Weekly"; (4)
"Daily". An index score was calculated by adding the scores for the two items, with a possible range from 2 to 8 .

We used a validated Norwegian translation of the Life Events Checklist (LEC) to assess exposure to potentially traumatic events (Halvorsen and Stenmark 2010). The LEC is a 17-item self-report questionnaire, but we administered it as part of the structured interview. The LEC has good temporal stability and reliability (Gray et al. 2004).

We used the Structured Clinical Interview for DSM-IV PTSD Module (SCID-PTSD) to determine a current PTSD diagnosis in the last month. The SCID-PTSD is based on the criteria from the Diagnostic and Statistical Manual of Mental Disorders, version IV (DSM-IV) (First et al. 1996). We also assessed for the worst potential traumatic event ever and each PTSD symptom in the last month.

The Structured Interview for Disorders of Extreme Stress (SIDES) is a clinical structured interview with 48 items and was used to assess the seven symptom domains of complex PTSD/ DESNOS (Disorders of Extreme Stress Not Otherwise Specified) (Pelcovitz et al. 1997): (I) alterations in affect and impulse regulation; (II) alterations in consciousness or attention; (III) alterations in self-perception; (IV) alterations in perception of the perpetrator (not required for a DESNOS diagnosis); (V) alteration in relations with others; (VI) somatization, and (VII) alterations in systems of meaning. SIDES has good psychometric properties, with reported kappa values of 0.8 and internal consistency of 0.96 . We used a Norwegian translation of SIDES developed by the Psychological Trauma Research Group at the University of Oslo. (SIDES version 1997(2) revised in7/2003). In our study, SIDES had a Cronbach's alpha of 0.89 .

We assessed for Chronic pain using the SIDES Subscale VI b question: "I suffer from chronic pain (circle items that apply) ", with the response alternatives (1) "Yes" and (2) "No". Chronic pain was defined as a longlasting pain stretching over many years, and all patients indicated that their chronic pain either began after the traumatic event ("Was this true for you after the experience?") or had been present for as long as they could remember ("Has this been true for you for as long as you can remember?").

We assessed Chronic pain at clinical levels with the SIDES Subscale VI $b$ question"How true has this been for you in the last month" with the following five response categories: 1) "None; not at all", 2) "Some trouble-did not require medical attention", 3) "Visited a doctor, more than one medicine without relief", 4) Several doctor visits, a hospital admission, and/or invasive diagnostic tests", and 5) "Not applicable". The response categories 1,2 and 5 were collapsed into the category "Chronic pain at nonclinical levels", and response categories 3 and 4 were collapsed into the category "Chronic pain at clinical levels". 
We identified Pain locations as endorsements of three items from the SIDES Scale VI. The first item was from the SIDES Subscale VI a, and stated: "I have trouble with abdominal pain". The second item was from the SIDES Subscale VI b, and stated "I suffer from chronic pain" with 6 response alternatives and the possibility to endorse all that applied: "in your arms and legs", "in your back", "in your joints", "during urination", "headaches", "elsewhere". The third item was from the SIDES Subscale VI c and stated "I suffer from chest pain".

The total number of pain locations was constructed by summing all the individual pains identified from the three items of the SIDES Subscales VI $a, b$ and $c$.

We used the M.I.N.I. International Neuropsychiatric Interview 5.0.0 (M.I.N.I.) to assess 21 Axis I DSM-IV disorders, although we did not include the modules for PTSD and anti-social personality disorder (Sheehan et al. 1998). We used a Norwegian version of the M.I.N. I. which has been validated in a sample of psychiatric patients (Mordal et al. 2010). We calculated the Total number of current diagnoses by adding all the assessed M.I.N.I. 5.0.0. current diagnoses.

We used a Norwegian translation of the Impact of Event Scale-revised (IES-R) to assess the presence and intensity of posttraumatic stress symptoms during the last week (Weiss and Marmar 1997; Heir et al. 2010). The IES-R is a 22-item self-report questionnaire, with a standard cut-off score of $\geq 33$ to indicate a PTSD diagnosis (Creamer et al. 2003). In our study, the IES-R had a Cronbach's alpha of 0.94 .

We used a validated Norwegian translation of the Hopkins Symptom Checklist (HSCL-25) to measure depression and anxiety. The HSCL-25 is a 25 -item selfreport questionnaire assessing depression and anxiety during the last week (Derogatis et al. 1974). It has two subscales assessing depression and anxiety, with cut-offscores $>1.75$ for both subscales to indicate likely depression and anxiety disorders. The HSCL-25 has been validated in refugee populations and has good psychometric properties (Mollica et al. 1987; Renner and Salem 2009; Lavik et al. 1999). We calculated a Cronbach's alpha of 0.91 for the total scale HSCL-25 in our study. The anxiety subscale of the HSCL-25 had a Cronbach's alpha of 0.89 , while the depression subscale of the HSCL-25 had a Cronbach's alpha of 0.92 .

\section{Statistical procedures}

We used frequencies, means and standard deviations to describe the sample on demographic and trauma variables. Exact chi-square tests were used to compare differences between outpatients with and without chronic pain on demographic, social, trauma variables, as well as gender differences in the location of pains. We also used exact chisquare tests to assess differences in the locations of chronic pain and clinical levels of chronic pain between outpatients with and without PTSD, as well as the presence of current PTSD diagnosis in outpatients with or without chronic pain at clinical levels. We used t-tests to assess differences in types of traumatic exposures, and differences in psychiatric symptom severity between outpatients with and without chronic pain. We also used t-tests to identify differences in the total number of chronic pains between outpatients with and without PTSD. We calculated a phi coefficient to estimate the strength of statistically significant differences in the chi-square analyses, and an eta squared coefficient for the $t$ tests. Missing data was handled by using the pairwise exclusion of cases. In order to minimize errors of multiple testing, we adjusted other p-values using the Holm correction (Aickin and Gensler 1996). Cronbach's alpha coefficients were calculated for all scales. All tests were two-tailed and alpha was set at $\mathrm{p}=0.05$. All statistical analyses were performed on IBM SPSS Statistics 19 (IBM SPSS Statistics Inc, Armonk, New York, USA).

\section{Results}

Demographic, social, and trauma characteristics

There were 36 (59\%) men and 25 (41\%) women originated from some 21 countries from four continents. The mean age for the whole sample was $41.7(\mathrm{SD}=9.6)$ years. The mean of total types of exposures to traumatic events was $10(\mathrm{SD}=2.4)$ for men and $9(\mathrm{SD}=3.1)$ for women. The mean time since the traumatic event was 17.8 years $(\mathrm{SD}=10.2)$ for men, and 16.5 years $(\mathrm{SD}=8.8)$ for women, and the mean length of stay in Norway was 15.8 years $(\mathrm{SD}=6.4$ years $)$. A current PTSD diagnosis was found in $50(82 \%)$ of the outpatients. There were no significant differences between the outpatients with and without chronic pain on demographic, social variables, and trauma exposures. Demographic and social variables are presented in Table 1.

\section{Chronic pain, traumatic experiences, and severity of psychiatric symptomatology}

All except one outpatient reported chronic pain in at least one location (98\%), and 4 outpatients (7\%) identified eight chronic pain locations. The mean number of pain locations was $4.6(\mathrm{SD}=2.1)$. The most prevalent chronic pain locations were head (80\%), chest (74\%), arms/legs (66\%), back (62\%), and stomach (57\%).

No significant differences in specific or total number of types of traumatic exposures were found between outpatients with or without chronic pain. Frequencies and p-values are presented in Table 2.

Outpatients with chronic pain at clinical levels had significantly more symptoms of PTSD $(\mathrm{M}=55.0 ; \mathrm{SD}=15.5)$ than outpatients without chronic pain $(\mathrm{M}=42.8 ; \mathrm{SD}=$ 19.1) [ $\mathrm{t}(54)=-2.56, \mathrm{p}=0.013$, adjusted $\mathrm{p}=0.039$ ]. The 
Table 1 Demographics and social variables

\begin{tabular}{|c|c|c|c|c|c|}
\hline & $\begin{array}{l}\text { No Chronic pain* } \\
(n=21) \mathrm{N}(\%)\end{array}$ & $\begin{array}{l}\text { Chronic pain* } \\
(n=40) \text { N (\%) }\end{array}$ & $\mathrm{Chi}^{2} / \mathrm{t}$-value & p-value & p-value§ \\
\hline \multicolumn{6}{|l|}{ Gender $(n=61)$} \\
\hline Women & $8(32.0)$ & $17(68.0)$ & 0.110 & 0.790 & 1.000 \\
\hline Men & $13(36.1)$ & $23(63.7)$ & & & \\
\hline \multicolumn{6}{|l|}{ Marital status $(n=61)$} \\
\hline Single & $7(58.3)$ & $5(41.7)$ & 4.549 & 0.111 & 0.888 \\
\hline Married & $9(25.0)$ & $27(75.0)$ & & & \\
\hline Divorced & $5(38.5)$ & $8(61.5)$ & & & \\
\hline \multicolumn{6}{|l|}{ Ethnicity $(n=61)$} \\
\hline Eastern Europe & $7(31.8)$ & $15(68.2)$ & 0.160 & 0.941 & 0.941 \\
\hline Africa + Middle East & $9(34.6)$ & $17(65.4)$ & & & \\
\hline Other & $5(38.5)$ & $8(61.5)$ & & & \\
\hline \multicolumn{6}{|l|}{ Living conditions ( $n=60$ ) } \\
\hline Living alone & $6(50.0)$ & $6(50.0)$ & 1.875 & 0.304 & 1.000 \\
\hline Living with family/others & $14(29.2)$ & $34(70.8)$ & & & \\
\hline \multicolumn{6}{|l|}{ Employment $(n=53)$} \\
\hline Not employed & $11(34.4)$ & $21(65.6)$ & 1.607 & 0.471 & 1.000 \\
\hline Part time employed & $5(50.0)$ & $4(50.0)$ & & & \\
\hline Employed & $3(23.1)$ & $10(76.9)$ & & & \\
\hline \multicolumn{6}{|l|}{ Having friends $(n=57)$} \\
\hline Having no friends & $5(22.7)$ & $17(77.3)$ & 1.299 & 0.381 & 1.000 \\
\hline Having friends & $13(37.1)$ & $22(62.9)$ & & & \\
\hline \multicolumn{6}{|l|}{ Proficiency of the Norwegian language $(n=56)$} \\
\hline Low & $2(40.0)$ & $3(60.0)$ & 3.242 & 0.183 & 1.000 \\
\hline Medium & $4(18.2)$ & $18(81.8)$ & & & \\
\hline High & $12(41.4)$ & $17(67.9)$ & & & \\
\hline Social integration in Norway $(n=57)$ & $10.9(2.1)$ & $9.3(2.6)$ & 1.526 & 0.021 & 0.252 \\
\hline Social integration in ethnic community $(n=56)$ & $3.9(1.3)$ & $3.3(1.1)$ & 0.924 & 0.058 & 0.522 \\
\hline Years in Norway $(n=56)$ \# Mean (SD) & $17(9.0)$ & $16(6.1)$ & 0.487 & 0.628 & 1.000 \\
\hline Education $(n=55)$ \# Mean (SD) & $14(4.5)$ & $12(3.3)$ & 2.058 & 0.045 & 0.495 \\
\hline Age $(n=61) \#$ Mean $(S D)$ & $39(11.4)$ & $43(8.2)$ & -1.942 & 0.057 & 0.570 \\
\hline
\end{tabular}

Exact chi-square tests were performed; $\left(^{*}\right)$ Chronic pain at clinical levels; (\#) $T$-test; (§) p-values adjusted for multiple testing by Holm adjustment; in bold significant $p$-values.

mean difference was -12.25 , 95\% CI:-21.84 to -2.65 , and the magnitude was small (eta squared $=0.017$ ).

Outpatients with chronic pain at clinical levels had significantly higher distress levels than those without chronic pain at clinical levels, more depressive symptoms, more anxiety symptoms, and more DESNOS symptoms. Means, $\mathrm{t}$-values and $\mathrm{p}$-values are presented in Table 3.

\section{Chronic pain and gender}

Women had significantly more chronic pain locations $(\mathrm{M}=5.28 ; \quad \mathrm{SD}=1.9)$ than men $(\mathrm{M}=4.08 ; \quad \mathrm{SD}=2.13)$ [t $(59)=-2.27, \mathrm{p}=0.027]$. The mean difference was $=$
-1.20 , 95\% CI:-2.25 to -0.14 , and the magnitude was small (eta squared $=0.017$ ).

There were no significant differences between men and women in prevalence of chronic pain at clinical levels $\left[\chi^{2}\right.$ $(1, \mathrm{n}=61)=0.110, \mathrm{p}=.790$, phi $=.04]$, or prevalence of comorbid PTSD and chronic pain $\left[\chi^{2}(1, \mathrm{n}=61)=0.033, \mathrm{p}=\right.$ 1.000 , phi $=-0.02]$. The frequency of chronic pain by gender is presented in the Table 4 .

\section{Chronic pain and PTSD}

Seventy percent of the outpatients with chronic pain at clinical levels had also a current PTSD diagnosis, but no 
Table 2 Differences between groups on traumatic exposures

\begin{tabular}{|c|c|c|c|c|}
\hline Variables & No Chronic pain* $(n=21) \mathrm{N}(\%)$ & Chronic pain* $(n=40) N(\%)$ & $\mathrm{Chi}^{2}$ & p-value \\
\hline \multicolumn{5}{|l|}{ Traumatic experiences (LEC) } \\
\hline Natural disaster & $6(25.0)$ & $18(75.0)$ & 1.557 & 0.275 \\
\hline Fire or explosion & $13(28.3)$ & $33(71.7)$ & 3.150 & 0.117 \\
\hline Transportation accident & $11(27.5)$ & $29(72.5)$ & 2.469 & 0.158 \\
\hline Serious accident at work or at home & $9(31.0)$ & $20(69.0)$ & 0.282 & 0.788 \\
\hline Exposure to toxic substance & $4(40.0)$ & $6(60.0)$ & 0.165 & 0.725 \\
\hline Physical assault & $17(32.7)$ & $35(67.3)$ & 0.469 & 0.706 \\
\hline Assault with weapon & $16(34.8)$ & $30(65.2)$ & 0.011 & 1.000 \\
\hline Sexual assault & $7(38.9)$ & $11(61.1)$ & 0.225 & 0.769 \\
\hline Other unwanted sexual experience & $5(35.7)$ & $9(64.3)$ & 0.013 & 1.000 \\
\hline Combat or exposure to a war-zone & $13(28.9)$ & $32(71.1)$ & 2.330 & 0.220 \\
\hline Captivity & $11(34.4)$ & $21(65.6)$ & 0.000 & 1.000 \\
\hline Life-threatening illness or injury & $8(27.8)$ & $21(72.4)$ & 1.146 & 0.419 \\
\hline Severe human suffering & $19(35.2)$ & $35(64.8)$ & 0.120 & 1.000 \\
\hline Sudden, violent death & $13(31.7)$ & $28(68.3)$ & 0.410 & 0.574 \\
\hline Sudden, unexpected death of someone close to you & $16(31.4)$ & $35(68.6)$ & 1.285 & 0.291 \\
\hline Serious injury, harm, or death you caused to someone else & $2(20.0)$ & $8(80.0)$ & 1.103 & 0.470 \\
\hline Any other stressful event or experience & $18(33.3)$ & $36(66.7)$ & 0.249 & 0.683 \\
\hline Total types of traumatic exposures \# Mean (SD) & $9(2.6)$ & $10(2.8)$ & -1.679 & 0.094 \\
\hline
\end{tabular}

Exact chi-square tests were performed; $\left(^{*}\right)$ Chronic pain at clinical levels; (\#) T-test; LEC = Life Events Checklist.

significant difference between the groups with and without chronic pain in having a current PTSD diagnosis was found $\left[\chi^{2}(1, \mathrm{n}=61)=1.44, \mathrm{p}=0.164\right.$, phi $\left.=0.20\right]$.

Further, $88 \%$ of the outpatients with current PTSD diagnosis had chronic pain at clinical levels, but no significant difference between the groups with and without current PTSD in having a chronic pain at clinical levels was found $\left[\chi^{2}(1, \mathrm{n}=61)=1.44, \mathrm{p}=0.164\right.$, phi $\left.=0.20\right]$. Comorbid PTSD and chronic pain at clinical levels was found in 35 outpatients (57\%).

No significant difference in pain locations was found in outpatients with and without current PTSD diagnosis. Further, no significant difference was found between outpatients with PTSD diagnosis $(\mathrm{M}=4.74 ; \mathrm{SD}=2.1)$ and those without it $(\mathrm{M}=3.82 ; \mathrm{SD}=2.2)[\mathrm{t}(59)=-1.33$, $\mathrm{p}=0.19$, adjusted $\mathrm{p}=1.000]$ in the total number of chronic pain locations. The mean difference was $=-0.92,95 \%$ CI:2.31 to 0.46 , and the magnitude was small to moderate (eta squared $=0.03$ ). Frequencies and $p$-values are presented in Table 5

\section{Discussion}

\section{Chronic pain and traumatic exposures}

In our study of 61 psychiatric outpatients, forty $(65.6 \%)$ reported chronic pain at clinical levels. This is three and a half times higher than rates of chronic pain found in the general population (19\%) (Breivik et al. 2006), similar to rates found in other investigations of refugee populations (Jamil et al. 2006; Cheung 1994), and even still higher than a study of pain in refugees resettled in Sweden (Hermansson et al.

Table 3 Group comparisons on psychiatric symptoms severity and number of diagnoses

\begin{tabular}{|c|c|c|c|c|c|}
\hline \multirow[t]{2}{*}{ Dependent variables } & \multirow{2}{*}{$\begin{array}{l}\text { No chronic pain* }(n=21) \\
\text { Mean }(S D)\end{array}$} & \multicolumn{4}{|l|}{ Chronic pain* $(n=40)$} \\
\hline & & Mean (SD) & t-value & p-value & p-value§ \\
\hline$\overline{I E S-R}$ & $42.8(19.1)$ & $55.0(15.5)$ & -2.558 & 0.013 & 0.050 \\
\hline HSCL-25 total scale & $2.3(0.6)$ & $2.9(0.5)$ & -3.503 & 0.001 & 0.006 \\
\hline HSCL- 25- Depression scale & $2.4(0.7)$ & $2.0(0.6)$ & -3.040 & 0.004 & 0.016 \\
\hline HSCL- 25-Anxiety scale & $2.3(0.6)$ & $2.8(0.6)$ & -3.302 & 0.002 & 0.010 \\
\hline SIDES severity & $35.5(18.2)$ & $46.5(17.0)$ & -2.337 & 0.023 & 0.069 \\
\hline Number of current diagnoses & $3.8(2.6)$ & $5.0(2.5)$ & -1.901 & 0.078 & 0.078 \\
\hline
\end{tabular}

T-tests were performed; $\left(^{*}\right)$ Chronic pain at clinical levels; $(\S)$ p-values adjusted for multiple testing by Holm adjustment; in bold significant $\mathrm{p}$-values; IES-R = Impact of Event Scale Revised; HSCL-25 = Hopkins Symptom Checklist Scale; SIDES = Structured Interview for Disorders of Extreme Stress. 
Table 4 Frequency of chronic pain locations in gender

\begin{tabular}{|c|c|c|c|c|c|c|c|c|c|}
\hline \multirow[b]{2}{*}{ Variables } & \multicolumn{2}{|c|}{ Men $(n=36)$} & \multicolumn{2}{|c|}{ Women $(n=25)$} & \multicolumn{2}{|c|}{ Total population $(n=61)$} & \multirow[t]{2}{*}{$\mathrm{Chi}^{2} / \mathrm{t}$-value } & \multirow[t]{2}{*}{ p-value } & \multirow[t]{2}{*}{ p-value§ } \\
\hline & $\mathrm{N}$ & $\%$ & $\mathbf{N}$ & $\%$ & $\mathrm{~N}$ & $\%$ & & & \\
\hline \multicolumn{10}{|l|}{ Chronic pain locations* } \\
\hline Stomach pain & 16 & 45.7 & 19 & 54.3 & 35 & 57.3 & 6.007 & 0.019 & 0.224 \\
\hline Chest pain & 28 & 62.2 & 17 & 37.8 & 45 & 73.8 & 0.729 & 0.555 & 1.000 \\
\hline Arms/legs pain & 21 & 52.5 & 19 & 47.5 & 40 & 65.6 & 2.040 & 0.181 & 1.000 \\
\hline Back pain & 19 & 50.0 & 19 & 50.0 & 38 & 62.3 & 3.387 & 0.106 & 0.957 \\
\hline Joints pain & 16 & 48.5 & 17 & 51.5 & 33 & 54.1 & 3.297 & 0.116 & 0.930 \\
\hline Head pain & 27 & 55.1 & 22 & 44.9 & 49 & 80.3 & 1.578 & 0.328 & 1.000 \\
\hline Pain during urination & 10 & 50.0 & 10 & 50.0 & 20 & 32.8 & 1.000 & 0.408 & 1.000 \\
\hline Other pain locations & 10 & 52.6 & 9 & 47.6 & 19 & 31.1 & 0.465 & 0.579 & 1.000 \\
\hline Chronic pain at clinical levels & 23 & 57.5 & 17 & 42.5 & 40 & 100 & 0.110 & 0.790 & - \\
\hline Total number of pain locations \# Mean (SD) & \multicolumn{2}{|c|}{$4.08(2.13)$} & \multicolumn{2}{|c|}{$5.28(1.86)$} & $4.57(2.09)$ & & -2.271 & 0.027 & - \\
\hline
\end{tabular}

Exact chi-square tests were performed; $\left(^{*}\right)$ Chronic pain at clinical levels; (\#) T-tests; ( $§$ ) p-values adjusted for multiple testing by Holm adjustment; in bold significant $\mathrm{p}$-values.

2001). Further, we found a mean number of 4.6 chronic pain locations in our outpatients, which is comparable with the number of body parts with pain reported after migration in a previous study (Carlsson et al. 2005), and higher than a study from the Netherlands which found a mean of 2 chronic conditions (Gerritsen et al. 2006). Other studies among Bhutanese, Bosnian and Kosovar refugees exposed to torture found higher number of somatic complains than in our study (van Ommeren et al. 2002; Schubert and Punamäki 2010. The most frequent chronic pain location in our sample was in the head, which is in line with findings from other studies of refugee populations (Moisander and Edston 2003; Moore and Boehnlein 1991). An increase in pain symptoms (pain in the head, pain in the back and pain in the feet) over a ten year period was found in a study of tortured refugees resettled in Denmark (Olsen et al. 2007). It seems that in the case of pain, the passage of time does not heal all wounds, but rather can aggravate them.

We found no significant differences in exposure to specific types of traumatic events between outpatients with chronic pain at clinical levels and those without. One possible explanation can be that all outpatients were exposed to multiple types of traumatic events, thus making the two groups less distinct from each other. It may be difficult to compare only one type of traumatic exposure in refugees, given as a rule rather than as an exception, that they are usually exposed to multiple traumatic events during the pre- and trans-migration journey (Jamil et al. 2010; Pumariega et al. 2005). Further, the heterogeneity of the traumatic exposures seen in our patients may give rise to different pains. A Danish study of torture survivors

Table 5 Differences between groups on pain locations and total number of chronic pains

\begin{tabular}{|c|c|c|c|c|c|c|c|}
\hline \multirow[b]{2}{*}{ Variables } & \multicolumn{2}{|c|}{ No PTSD $(n=11)$} & \multicolumn{2}{|c|}{ PTSD $(n=50)$} & \multirow[t]{2}{*}{$\mathrm{Chi}^{2} / \mathrm{t}$-value } & \multirow[t]{2}{*}{$\mathrm{p}$-value } & \multirow[t]{2}{*}{ p-value } \\
\hline & $\mathbf{N}$ & $\%$ & $\mathbf{N}$ & $\%$ & & & \\
\hline \multicolumn{8}{|l|}{ Chronic pain locations* } \\
\hline Stomach pain & 5 & 14.3 & 30 & 87.7 & 0.780 & 0.504 & 1.000 \\
\hline Chest pain & 7 & 15.6 & 38 & 84.4 & 0.712 & 0.457 & 1.000 \\
\hline Arms/legs pain & 6 & 15.0 & 34 & 85.0 & 0.723 & 0.483 & 1.000 \\
\hline Back pain & 6 & 15.8 & 32 & 82.2 & 0.343 & 0.733 & 1.000 \\
\hline Joints pain & 6 & 18.2 & 27 & 81.8 & 0.001 & 1.000 & 1.000 \\
\hline Head pain & 7 & 14.3 & 42 & 85.7 & 2.366 & 0.203 & 1.000 \\
\hline Pain during urination & 2 & 10.0 & 18 & 90.0 & 1.299 & 0.312 & 1.000 \\
\hline Other pain locations & 3 & 15.8 & 16 & 84.2 & 0.094 & 1.000 & 1.000 \\
\hline Chronic pain at clinical levels & 5 & 12.5 & 35 & 87.5 & 2.406 & 0.164 & - \\
\hline Total number of pain locations \# (Mean (SD) & \multicolumn{2}{|c|}{$3.82(2.2)$} & \multicolumn{2}{|c|}{$4.74(2.1)$} & -1.331 & 0.190 & - \\
\hline
\end{tabular}

Exact chi-square tests were performed; (*) Chronic pain at clinical levels; (\#) T-tests; (§) p-values adjusted for multiple testing by Holm adjustment. 
found a relationship between the four types of torture (Palestinian hanging, falanga, beating and kicking of the head, and positional torture) and specific neuropathic pain conditions (Thomsen et al. 2000). Further, Leeuw and his colleagues found a difference in PTSD symptom severity between pain patients with either muscle tension pain or with headache pain, with the former group reporting higher rates of PTSD symptoms (Leeuw et al. 2007).

\section{Chronic pain and psychiatric symptomatology}

We found that outpatients with chronic pain at clinical levels had significantly more posttraumatic symptoms, although this result is barely significant after adjustment for multiple testing. They also had more psychiatric morbidity than outpatients without chronic pain, also after adjustment for multiple testing. The finding supports our first hypothesis, and is in line with other studies that found that chronic pain often accompanies mental disorders, influencing an increase in their severity (Lepine and Briley 2004; Ohayon 2004). Further, pain has been found to increase the level of psychological distress, especially depression and anxiety symptoms (Tsang et al. 2008). We also found that chronic pain at clinical levels was comorbid with PTSD, and the comorbidity was high (57\%) as compared with a study of Bosnian patients with PTSD (Avdibegovic et al. 2010), but lower than in a clinical sample of refugees with different national origins in Norway (Dahl et al. 2006) and Iraqi Gulf veterans refugees in USA (Jamil et al. 2006).

An explanation for the comorbidity between chronic pain and PTSD, as well as for a possible increase in the severity of PTSD symptomatology through the presence of pain, may be through the mutual maintenance mechanism.

The part of the second hypothesis that women would report significantly higher frequencies of chronic pain locations than men in our study was confirmed, which is in line with the mainstream research on gender differences in chronic pain prevalence (Unruh 1996; Tsang et al. 2008; Schubert and Punamäki 2010; Celentano et al. 1990). In contrast, a study on tortured refugees found no significant gender differences (Williams et al. 2010). The other parts of the second hypothesis that women would have more chronic pain at clinical levels and more PTSD and chronic pain comorbidity were not supported by our findings. The lack of gender differences on these items may be because the men participating in our sample also reported high levels of pain at the clinical level, such that the difference between men and women was minimized, and the limited size of our sample did not provide enough power to detect the gender difference reported elsewhere in the literature.

Our third hypothesis was not confirmed; we found no significant difference between patients with and without PTSD in the clinical level of chronic pain in any of the 8 pain locations. We were expecting that the presence of a
PTSD diagnosis would increase the prevalence of pain in any of the 8 locations where we measured the presence of chronic pain, but we found no evidence for this. One possible explanation may be that both groups have high rates of comorbidity with other psychiatric diagnoses, making them more similar to each other and possibly resulting in no significant difference in chronic pain at clinical levels.

Regarding clinical implications, the present study indicates that chronic pain should be assessed and addressed in the treatment of multi-traumatized refugees in outpatient psychiatric clinics, in addition to mental health problems, knowing that chronic pain can increase the duration and the severity of mental disorders (Villano et al. 2007; Carlsson et al. 2010).

Chronic pain and PTSD are two distinct disorders and they often occur together, and due to their mutual maintenance there is a need for assessment and treatment for both conditions in outpatients with a refugee background. The outpatients need to be made more aware about the intersection of chronic pain with PTSD. Improved awareness of the internal and external cues of both chronic pain and PTSD symptoms will help patients achieve more positive coping through both cognitive and behavioral strategies, and to break the vicious circle of mutual maintenance of chronic pain and PTSD.

The management of comorbid chronic pain and PTSD is still challenging due to the need for clinical evidence-based therapies from longitudinal studies, but the field is developing fast such that new combined therapies for both PTSD and chronic pain are being tested (Liedl et al. 2010).

Future research is needed in order to address more adequately the prevalence rates of chronic pain and comorbid chronic pain and PTSD in refugee populations resettled in a western country using longitudinal designs with control groups from the same ethnic group. Future research may also assess more chronic pain locations, a larger spectrum of stressors and trauma types, including losses, during pre-, trans and post-migration periods, more diagnoses including Axis II personality disorders, as well as socioeconomic and cultural factors.

\section{Strengths}

One strength of this study is that we used a clinical structured interview for assessing PTSD diagnosis. We found $100 \%$ agreement between the clinical structured interview (SCID-PTSD) and IES-R in assessing PTSD diagnosis, thus ensuring the validity of the PTSD diagnosis. The validity of the psychiatric diagnoses in refugee populations has been questioned in a number of articles (Hollifield et al. 2002; Al-Saffar et al. 2004), but the general view is that the traumatic reactions described in the diagnostic criteria of PTSD are consistent across cultures (Carlson and Rosser et al.1994). However, some specific reactions may be seen in 
certain cultures (Hinton and Lewis-Fernandez 2011). Another strength was the large diversity of our population, a diversity seen in many clinical settings in Norway (Fosse and Dersyd 2007). A further strength of this study was that we assessed the comorbidity between PTSD and chronic pain at the same time, using validated clinical instruments, ensuring that the PTSD diagnosis and the chronic pain condition were valid.

\section{Limitations}

Our study also has some methodological limitations. The comparisons of our study with other studies should be interpreted with caution, knowing that these comparisons are much influenced by the use of different instruments for assessing chronic pain, and in addition to this, they may assess different number of chronic pains. First, our sample size was relatively small and we used a crosssectional design without a control group which may limit the generalizability of the findings. Second, we did not use a physician's medical diagnosis or a widely used clinical instrument for assessing chronic pain locations and intensity, but instead a scale from one clinical interview created for assessing the DESNOS syndrome. This may limit our findings and conclusions with regard to the total number of chronic pain locations and chronic pain intensity, and the results should thus be interpreted with caution. Third, we did not assess when the chronic pain began to see if it was related to the development of the PTSD diagnosis, thus we do not know if the chronic pain was a result of the development of a PTSD diagnosis, or if these two are unrelated. Future research needs to assess more clearly the onset of chronic pain and how it is temporally related to a PTSD diagnosis. Fourth, our exclusion of outpatients with a lack of proficiency in the Norwegian language may have excluded many participants who would have otherwise been eligible, thus the prevalence rates may be biased and should be interpreted with caution. Fifth, the timeframe to complete and send back the Questionnaire was agreed to be one week after the clinical interview, but no clear date was chosen for the completion of several selfreported questionnaires like IES-R and HSCL-25 which assess the symptoms from the last 7 days. We are not sure if all the outpatients chose the same date to complete the self-reported questionnaires. Sixth, we have assessed some post-migration-living difficulties, but not all difficulties that resettled refugees in a Western country may encounter. There is evidence that the current living difficulties have a deep impact on the refugees and many acknowledge these difficulties as having a stronger impact on psychological health than previous exposure to traumatic events in the country of origin. Lastly, the majority of our sample reported multiple pain sites, and thus we do not know which pain site contributed more to the overall pain disability and intensity.

\section{Conclusions}

In our study we found high rates of PTSD and chronic pain, with a majority of outpatients reporting comorbidity between the two. Only a few studies in refugee populations have measured this comorbidity and found such a high level of PTSD and chronic pain at clinical levels. This comorbidity is related to increased severity of psychiatric symptoms and high psychiatric morbidity, possibly due to a mutual maintenance mechanism between the two conditions. Because of the mutual influence between the two disorders, it is important that they be assessed and treated together. Chronic pain should be acknowledged as an independent clinical entity, just in the same way as PTSD is acknowledged as a distinct psychiatric disorder. Further investigations into the comorbidity of PTSD with other somatic disorders, as well as the comorbidity of chronic pain with other psychiatric conditions, would help to identify factors associated with these comorbidities. Future studies should also include validated scales for postmigration-living difficulties which have been found to have a strong impact on the resettled refugees' mental health and quality of life.

\section{Competing interests}

The authors declare that they have no competing interests.

\section{Authors' contributions}

Concept: EH, TH, LL; Data collection: DST; Data analysis: DST, TWL; First draft: DST; Critical revisions: DST, JS, TWL, EH, TH, LL; Final manuscript read and approved: DST, JS, TWL, EH, TH, LL. All authors read and approved the final manuscript.

\section{Acknowledgments}

The study was founded by a grant from the Southern and Eastern Norway Regional Health Authority. The authors wish to express their gratitude to all the patients who took the effort to participate in the study, to the therapists who made referrals for the study, and the leadership of the Innlandet Hospital Trust, Oslo University Hospital, Lovisenberg Hospital Trust and Sørlandet Hospital Trust who approved this study. Special thanks for the Department of Public Health, Hedmark University College, Elverum, Norway for additional funding for the writing of this article. We wish to thank Priscilla Martinez Ph.D. with the help of English language and for comments on the article.

\section{Author details}

'Department of Public Health, Hedmark University College, Elverum, Norway. ${ }^{2}$ Norwegian Centre for Violence and Traumatic Stress Studies, Oslo, Norway. ${ }^{3} R$ \& D Department, Mental Health Services, Akershus University Hospital, Oslo, Norway. ${ }^{4}$ Division of Mental Health and Addiction, Oslo University Hospital, Oslo, Norway. ${ }^{5}$ Institute of Clinical Medicine, Faculty of Medicine, University of Oslo, Oslo, Norway. ${ }^{6}$ Centre for Child and Adolescent Mental Health, Eastern and Southern Norway, Oslo, Norway. ${ }^{7}$ Innlandet Hospital Trust, PO Box 104, N-2381 Brumunddal, Norway.

Received: 29 September 2014 Accepted: 3 March 2015 Published online: 15 March 2015

\section{References}

Ai, AL, Peterson, C, \& Ubelhor, D. (2002). War-related trauma and symptoms of posttraumatic stress disorder among adult Kosovar refugees. Journal of Traumatic Stress, 15(2), 157-160.

Aickin, M, \& Gensler, H. (1996). Adjusting for multiple testing when reporting research results: the Bonferroni vs Holm methods. American Journal of Public Health, 86(5), 726-728. 
Al-Saffar, S, Borga, P, Wicks, S, \& Hallstrom, T. (2004). The influence of the patients' ethnicity, socio-demographic conditions and strain on psychiatric diagnoses given at an outpatient clinic. Nordic Journal of Psychiatry, 58(6), 421-427.

American Psychiatric Association. (2000). Diagnostic and statistical manual of mental disorders (4 th ed., text revision). Washington, DC: Author.

American Psychiatric Association. (2013). Diagnostic and statistical manual of mental disorders (5 the ed.). Washington, DC: Author.

Andersen, T, Andersen, P, Vakkala, M, \& Elklit, A. (2012). The traumatised chronic pain patient-prevalence of posttraumatic stress disorder- PTSD and pain sensitization in two Scandinavian samples referred for pain rehabilitation. Scandinavian Journal of Pain, 3(1), 39-43.

Asmundson, GJ, Coons, MJ, Taylor, S, \& Katz, J. (2002). PTSD and the experience of pain: research and clinical implications of shared vulnerability and mutual maintenance models. Canadian Journal of Psychiatry, 47(10), 930-937.

Avdibegovic, E, Delic, A, Hadzibeganovic, K, \& Selimbasic, Z. (2010). Somatic diseases in patients with posttraumatic stress disorder. Medical Archives, 64(3), 154-157.

Baker, DG, Mendenhall, CL, Simbartl, LA, Magan, LK, \& Steinberg, JL. (1997). Relationship between posttraumatic stress disorder and self-reported physical symptoms in Persian Gulf War veterans. Archives of Internal Medicine, 157(18), 2076-2078.

Beck, J, \& Clapp, J. (2011). A different kind of comorbidity: understanding posttraumatic stress disorder and chronic pain. Psychological Trauma: Theory, Research, Practice and Policy, 3(2), 101-108.

Beckham, JC, Crawford, AL, Feldman, ME, Kirby, AC, Hertzberg, MA, Davidson, JR, \& Moore, SD. (1997). Chronic posttraumatic stress disorder and chronic pain in Vietnam combat veterans. Journal of Psychosomatic Research, 43(4), 379-389.

Breivik, H, Collett, B, Ventafridda, V, Cohen, R, \& Gallacher, D. (2006). Survey of chronic pain in Europe: prevalence, impact on daily life, and treatment. European Journal of Pain, 10(4), 287-333.

Bryant, RA, Marosszeky, JE, Crooks, J, Baguley, IJ, \& Gurka, JA. (2001). Posttraumatic stress disorder and psychosocial functioning after severe traumatic brain injury. Journal of Nervous and Mental Disorders, 189(2), 109-113.

Carinci, AJ, Mehta, P, \& Christo, PJ. (2010). Chronic pain in torture victims. Current Pain and Headache Reports, 14(2), 73-79.

Carlson, EB, \& Rosser-Hogan, R. (1994). Cross-cultural response to trauma: a study of traumatic experiences and posttraumatic symptoms in Cambodian refugees. Journal of Traumatic Stress, 7(1), 43-58.

Carlsson, JM, Mortensen, EL, \& Kastrup, M. (2005). A follow-up study of mental health and health-related quality of life in tortured refugees in multidisciplinary treatment. Journal of Nervous and Mental Disorders, 193(10), 651-657.

Carlsson, JM, Olsen, DR, Kastrup, M, \& Mortensen, EL. (2010). Late mental health changes in tortured refugees in multidisciplinary treatment. Journal of Nervous and Mental Disorders, 198(11), 824-828.

Celentano, DD, Linet, MS, \& Stewart, WF. (1990). Gender differences in the experience of headache. Social Science and Medicine, 30(12), 1289-1295.

Cheung, P. (1994). Posttraumatic stress disorder among Cambodian refugees in New Zealand. International Journal of Social Psychiatry, 40(1), 17-26.

Creamer, M, Bell, R, \& Failla, S. (2003). Psychometric properties of the impact of event scale - revised. Behavior Research and Therapy, 41(12), 1489-1496.

Dahl, S, Dahl, Cl, Sandvik, L, \& Hauff, E. (2006). Chronic pain in traumatized refugees. Tidsskrift for Norsk Laegeforeningen, 126(5), 608-610.

Defrin, R, Ginzburg, K, Solomon, Z, Polad, E, Bloch, M, Govezensky, M, \& Schreiber, S. (2008). Quantitative testing of pain perception in subjects with PTSDimplications for the mechanism of the coexistence between PTSD and chronic pain. Pain, 138(2), 450-459.

Derogatis, LR, Lipman, RS, Rickels, K, Uhlenhuth, EH, \& Covi, L. (1974). The Hopkins symptom checklist (HSCL). A measure of primary symptom dimensions. Modern Problems of Pharmacopsychiatry, 7, 79-110.

Difede, J, Jaffe, AB, Musragi, G, Perry, S, \& Yurt, R. (1997). Determinants of pain expression in hospitalized burn patients. Pain, 72(1-2), 245-251.

Dunn, AS, Julian, T, Formolo, LR, \& Green, DR. (2011). Preliminary analysis of posttraumatic stress disorder screening within specialty clinic setting for OIF/ OEF veterans seeking care for neck or back pain. Journal of Rehabilitation and Research Development, 48(5), 493-502.

Elklit, A, Norregaard, J, \& Tibor, B. (1998). [Occurrence and type of traumatic experiences among young Bosnian refugees in Denmark] Forekomst og art af traumatiserende begivenheder hos unge bosniske flygtninge i Danmark. Ugeskrift forlaeger, 160(29), 4310-4314.

Ferrada-Noli, M, Asberg, M, Ormstad, K, Lundin, T, \& Sundbom, E. (1998). Suicidal behavior after severe trauma. Part 1: PTSD diagnoses, psychiatric comorbidity, and assessments of suicidal behavior. Journal of Traumatic Stress, $11(1), 103-112$.
First, MB, Spitzer, RL, Gibbon, M, \& Williams, JB. (1996). Structured Clinical Interview for the DSM-IV Axis I Disorders - Patient Edition (SCIDI/P, version 2.0). New York: Biometrics Research Department New York State Psychiatric Institute.

Foa, EB, Steketee, G, \& Rothbaum, BO. (1989). Behavioral/cognitive conceptualizations of post-traumatic stress disorder. Behavior Therapy, 20(2), 155-176.

Fosse, R, \& Dersyd, AK. (2007). Forekomsten av traumatiserte pasienter ved distriktpsykiatriske sentre i spesialisthelsetjenesten [The incidence of trauma patients at community mental health centers in the specialist health clinics]. Oslo: NKVTS, RVTS- $\varnothing$.

Gerritsen, AA, Bramsen, I, Deville, W, van Willigen, LH, Hovens, JE, \& van der Ploeg, HM. (2006). Physical and mental health of Afghan, Iranian and Somali asylum seekers and refugees living in the Netherlands. Social Psychiatry and Psychiatric Epidemiology, 41(1), 18-26.

Gray, MJ, Litz, BT, Hsu, JL, \& Lombardo, TW. (2004). Psychometric properties of the life events checklist. Assessment, 11(4), 330-341.

Halvorsen, JO, \& Stenmark, H. (2010). Narrative exposure therapy for posttraumatic stress disorder in tortured refugees: a preliminary uncontrolled trial. Scandinavian Journal of Psychology, 51(6), 495-502.

Heir, T, Piatigorsky, A, \& Weisæth, L. (2010). Posttraumatic stress symptom clusters associations with psychopathology and functional impairment. Journal of Anxiety Disorders, 24(8), 936-940.

Herman, JL. (1992). Complex PTSD: a syndrome in survivors of prolonged and repeated trauma. Journal of Traumatic Stress, 5(3), 377-391.

Hermansson, AC, Thyberg, M, Timpka, T, \& Gerdle, B. (2001). Survival with pain: an eight-year follow-up of war-wounded refugees. Medicine, Conflict, and Survival, 17(2), 102-111.

Hermansson, AC, Timpka, T, \& Thyberg, M. (2002). The mental health of warwounded refugees: an 8-year follow-up. The Journal of Nervous and Mental Disease, 190(6), 374-380.

Hinton, DE, \& Lewis-Fernandez, R. (2011). The cross-cultural validity of posttraumatic stress disorder: implications for DSM-5. Depression and Anxiety, 28(9), 783-801.

Hjellset, VT, Ihlebæk, CM, Bjørge, B, Eriksen, HR, \& Høstmark, AT. (2011). Healthrelated quality of life, subjective health complains, psychological distress and coping in Pakistani immigrant women with and without the metabolic syndrome. Journal of Immigrant Minority Health, 13(4), 732-741.

Hollifield, M, Warner, TD, Lian, N, Krakow, B, Jenkins, JH, Kelser, J, Stevenson, J, \& Westermeyer, J. (2002). Measuring trauma and health status in refugees: a critical review. JAMA 2002, 288(5), 611-621.

Jamil, H, Nassar-McMillan, S, Lambert, R, Wang, Y, Ager, J, \& Arnetz, B. (2010). Pre-and post-displacement stressors and time of migration as related to self-rated health among Iraqi immigrants and refugees in Souteast Michigan. Medicine, Conflict, and Survival, 26(3), 207-222.

Jamil, H, Nassar-McMillan, SC, Salman, WA, Tahar, M, \& Jamil, LH. (2006). Iraqi Gulf War veteran refugees in the U.S.: PTSD and physical symptoms. Social Work and Health Care, 43(4), 85-98.

Jaranson, JM, Butcher, J, Halcon, L, Johnson, DR, Robertson, C, Savik, K, Spring, M, $\&$ Westermeyer, J. (2004). Somali and Oromo refugees: correlates of torture and trauma history. American Journal of Public Health, 94(4), 591-598.

Jenewein, J, Wittmann, L, Moergeli, H, Creutzig, J, \& Schnyder, U. (2009). Mutual influence of posttraumatic stress disorder symptoms and chronic pain among injured accident survivors: a longitudinal study. Journal of Traumatic Stress, 22(6), 540-548.

Johnson, H, \& Thompson, A. (2008). The development and maintenance of posttraumatic stress disorder (PTSD) in civilian adult survivors of war trauma and torture: a review. Clinical Psychology Review, 28(1), 36-47.

Kummar, B, Grøtvedt, L, Meyer, HE, Søgaard, AJ, \& Strand, BH. (2008). The Oslo immigrant health profile. Rapport 2008:7. Oslo: Norwegian institute of public health.

Lavik, NJ, Hauff, E, Skrondal, A, \& Solberg, O. (1996). Mental disorder among refugees and the impact of persecution and exile: some findings from an out-patient population. British Journal of Psychiatry, 169(6), 726-732.

Lavik, NJ, Hauff, E, Solberg, O, \& Laake, P. (1999). The use of self-reports in psychiatric studies of traumatized refugees: validation and analysis of HSCL-25. Nordic Journal of Psychiatry, 53(1), 17-20.

Lepine, J-P, \& Briley, M. (2004). The epidemiology of pain in depression. Human Psychopharmacology, 19(Suppl 1), S3-S7.

Leeuw, M, Goossens, ME, Linton, SJ, Crombez, G, Boersma, K, \& Vlaeyen, JW. (2007). The fear-avoidance model of musculoskeletal pain: current state of scientific evidence. Journal of Behavioral Medicine, 30(1), 77-94.

Liedl, A, \& Knaevelsrud, C. (2008). Chronic pain and PTSD: the perpetual avoidance model and its treatment implications. Torture, 18(2), 69-76.

Liedl, A, O'Donnell, M, Creamer, M, Silove, D, McFarlane, A, Knaevelsrud, C, \& Bryant, RA. (2010). Support for the mutual maintenance of pain and post- 
traumatic stress disorder symptoms. Psychological Medicine, 40(07), 1215-1223.

Moeller-Bertram, T, Keltner, J, \& Strigo, IA. (2012). Pain and post traumatic stress disorder - review of clinical and experimental evidence. Neuropharmacology 2012, 62(2), 586-597.

Moisander, PA, \& Edston, E. (2003). Torture and its sequel-a comparison between victims from six countries. Forensic Science International, 137, 133-140.

Mollica, RF, Wyshak, G, de Marneffe, D, Khuon, F, \& Lavelle, J. (1987). Indochinese versions of the Hopkins Symptom Checklist-25: a screening instrument for the psychiatric care of refugees. American Journal of Psychiatry, 144(4), 497-500.

Moore, LJ, \& Boehnlein, JK. (1991). Posttraumatic stress disorder, depression, and somatic symptoms in U.S. Mien patients. Journal of Nervous and Mental Disorders, 179(12), 728-733.

Mordal, J, Gundersen, O, \& Bramness, JG. (2010). Norwegian version of the MiniInternational Neuropsychiatric Interview: feasibility, acceptability and test-retest reliability in an acute psychiatric ward. European Psychiatry, 25(3), 172-177.

Norman, SB, Stein, MB, Dimsdale, JE, \& Hoyt, DB. (2008). Pain in the aftermath of trauma is a risk factor for post-traumatic stress disorder. Psychological Medicine, 38(4), 533-542.

Norton, PJ, \& Asmundson, GJG. (2003). Amending the fear-avoidance model of chronic pain: What is the role of physiological arousal? Behavior Therapy, 34(1), 17-30.

Ohayon, MM. (2004). Specific characteristics of the pain/depression association in the general population. Journal of Clinical Psychiatry, 65(Suppl 12), 5-9.

Olsen, DR, Montgomery, E, Bøjholm, S, \& Foldspang, A. (2007). Prevalence of pain in the head, back and feet in refugees previously exposed to torture: a ten-year follow-up study. Disability and Rehabilitation, 29(2), 163-171.

O'Toole, BI, \& Catts, SV. (2008). Trauma, PTSD, and physical health: an epidemiological study of Australian Vietnam veterans. Journal of Psychosomatic Research, 64(1), 33-40.

Palic, S, \& Elklit, A. (2014). Personality dysfunction and complex posttraumatic stress disorder among chronically traumatized Bosnian refugees. Journal of Nervous and Mental Disorders, 202(2), 111-118.

Pelcovitz, D, van der Kolk, B, Roth, S, Mandel, F, Kaplan, S, \& Resick, P. (1997). Development of a criteria set and a structured interview for disorders of extreme stress (SIDES). Journal of Traumatic Stress, 10(1), 3-16.

Prip, K, Persson, AL, \& Sjolund, BH. (2011). Self-reported activity in tortured refugees with long-term sequelae including pain and the impact of foot pain from falanga: a cross-sectional study. Disability and Rehabilitation, 33(7), 569-578.

Pumariega, AJ, Rothe, E, \& Pumariega, JB. (2005). Mental health in immigrants and refugees. Community Mental Health Journal, 41(5), 581-597.

Renner, W, \& Salem, I. (2009). Post-traumatic stress in asylum seekers and refugees from Chechnya, Afghanistan, and West Africa: gender differences in symptomatology and coping. International Journal of Social Psychiatry, 55(2), 99-108.

Roth, G, Ekblad, S, \& Agren, H. (2006). A longitudinal study of PTSD in a sample of adult mass-evacuated Kosovars, some of whom returned to their home country. European Psychiatry, 21(3), 152-159.

Schneiderman, N, Ironson, G, \& Siegel, SD. (2005). Stress and health: psychological, behavioral, and biological determinants. Annual Review of Clinical Psychology, 1, 607-628.

Schubert, CC, \& Punamäki, RL. (2010). Mental health among torture survivors: cultural background, refugee status and gender. Nordic Journal of Psychiatry, 65(3), 175-182

Sharp, TJ. (2004). The prevalence of post-traumatic stress disorder in chronic pain patients. Current Pain and Headache Reports, 8(2), 111-115.

Sharp, TJ, \& Harvey, A. (2001). Chronic pain and post-traumatic stress disorder: mutual maintenance? Clinical Psychology Review, 21(6), 857-877.

Sheehan, DV, Lecrubier, Y, Sheehan, KH, Amorim, P, Janavs, J, Weiller, E, Hergueta, T, Baker, R, \& Dunbar, GC. (1998). The Mini-International Neuropsychiatric Interview (M.I. N.I.): the development and validation of a structured diagnostic psychiatric interview for DSM-IV and ICD-10. Journal of Clinical Psychiatry, 59(Suppl 20), 22-33. quiz 34-57.

Steel, Z, Silove, D, Phan, T, \& Bauman, A. (2002). Long-term effect of psychological trauma on the mental health of Vietnamese refugees resettled in Australia: a population based study. Lancet, 360(9339), 1056-1062.

Taloyan, M, Sundquist, J, \& Al-Windi, A. (2008). The impact of ethnicity and self-reported health on psychological well-being: a comparative study of Kurdish-born and Swedish-born people. Nordic Journal of Psychiatry, 62(5), 392-398.

Taylor, S. (2004). Advances in the Treatment of Posttraumatic Stress Disorder: Cognitive-Behavioral Approaches. New York: Springer.

Taylor, B, Carswell, K, \& de C Williams, AC. (2013). The interaction of persistent pain and post-traumatic re-experiencing: a qualitative study in torture survivors. Journal of Pain and Symptom Management, 46(4), 546-555.
Teegen, F, \& Vogt, S. (2002). [Torture survivors. A study of complex posttraumatic stress disorder] (German). Verhaltenstherapie und Verhaltensmedizin, 23, 91-106.

Thomsen, AB, Eriksen, J, \& Smidt-Nielsen, K. (2000). Chronic pain in torture survivors. Forensic Science International, 108(3), 155-163.

Tsang, A, Von Korff, M, Lee, S, Alonso, J, Karam, E, Angermeyer, MC, Borges, GL, Bromet, EJ, Demytteneare, K, de Girolamo, G, de Graaf, R, Gureje, O, Lepine, JP, Haro, JM, Levinson, D, Oakley Browne, MA, Posada-Villa, J, Seedat, S, \& Watanabe, M. (2008). Common chronic pain conditions in developed and developing countries: gender and age differences and comorbidity with depression-anxiety disorders. The Journal of Pain, 9(10), 883-891.

Unruh, AM. (1996). Gender variations in clinical pain experience. Pain, 65(2-3), 123-167.

Van Ommeren, M, Sharma, B, Sharma, GK, Komproe, I, Cardeña, E, \& de Jong, JT. (2002). The relationship between somatic and PTSD symptoms among Bhutanese refugee torture survivors: examination of comorbidity with anxiety and depression. Journal of Traumatic Stress, 15(5), 415-421.

Villano, CL, Rosenblum, A, Magura, S, Fong, C, Cleland, C, \& Betzler, TF. (2007). Prevalence and correlates of posttraumatic stress disorder and chronic severe pain in psychiatric outpatients. Journal of Rehabilitation Research and Development, 44(2), 167-178.

Waddell, G, Newton, M, Henderson, I, Sommerville, D, \& Main, CJ. (1993). Fear avoidance beliefs questionnaire (FABQ) and the role of fear-avoidance beliefs in chronic low back pain and disability. Pain, 52(2), 157-168.

Weiss, DS, \& Marmar, CR. (1997). The Impact of Event Scale-Revised. In JP Wilson \& TM Keane (Eds.), Assessing Psychological Trauma and PTSD (pp. 399-411). New York: Guilford Press.

WHO (2014). ICD-11 Beta Draft Complex post-traumatic stress disorder (CPTSD). Retrieved from http://id.who.int/icd/entity/585833559.

Williams, AC, Peña, CR, \& Rice, AS. (2010). Persistent pain in survivors of torture: a cohort study. Journal of Pain Symptoms and Management, 40(5), 715-722.

\section{Submit your next manuscript to BioMed Central and take full advantage of:}

- Convenient online submission

- Thorough peer review

- No space constraints or color figure charges

- Immediate publication on acceptance

- Inclusion in PubMed, CAS, Scopus and Google Scholar

- Research which is freely available for redistribution 